ISBN 978-93-84422-77-6

3rd International Conference on Innovations in Engineering \& Technology

(ICCET-2017)

Dubai (UAE) May 10-11, 2017

\title{
Retaining the Power Efficiency of Solar Panels with Super Hydrophobic Coating
}

\author{
Fesmi Abdul Majeed ${ }^{1}$, Waleed Salim Alqaydi ${ }^{2}$, Mohammed Sulaiman Alnaqbi ${ }^{2}$, Hamad Ebrahim \\ Alabduli $^{2}$, Rashed Mohammed Alqaydi ${ }^{2}$ and Abdelaziz Yousif Alnaqbi ${ }^{2}$ \\ ${ }^{1}$ Faculty, Higher College of Technology, Fujairah, UAE \\ ${ }^{2}$ Student, Higher College of Technology, Fujairah, UAE
}

\begin{abstract}
The detrimental effect of Weather conditions on solar panel power output efficiency is known. It is the major challenge to efficient utilization and reliability of solar energy on a worldwide scale. This paper presents an innovative yet easily industrially viable idea of improving solar panel efficiency by a super hydrophobic coating. The data is collected from experimental measurements conducted at the Higher Colleges of Technology, Fujairah, UAE.
\end{abstract}

Keywords: cleaning, super-hydrophobic, solar panel

\section{Introduction}

In a number of applications, especially in dusty environments, it is required for surfaces or walls to remain free from airborne particle deposition. A typical example is the deposition of dust on the solar panels or windshields in arid and dusty zones. The dust reduces the power generated by the solar devices or hinders the visibility through windshields. Large-scale solar installations already exist in China, Europe, the Middle East, Australia, and USA. These installations usually are located in sun-drenched desert areas where dry weather and winds sweep dust into the air and deposit it onto the surface of solar panel. Just like grime on a household window, that dust reduces the amount of light that can enter the business part of the solar panel, decreasing the amount of electricity produced. Clean water tends to be scarce in these areas, making it expensive to clean the solar panels. It is reported that a dust layer of 4 grams per square meter decreases solar power conversion

by 40 percent $[1,2]$.

This paper presents a design for an industrially manufacturing friendly design which is also self-reliant in terms of energy consumption and auto cleaning with minimal maintenance requirements. In order to meet these objectives, the following points have been carefully considered and incorporated:

a. Simple and viable, industrially manufacture-able scalable, with compact design.

b. Driven by Wind or Solar energy.

c. Automatic timed cleaning system incorporating the best research based technology.

d. Weather resistant, durable and efficient cleaning.

\section{Review on Current Cleaning Technology}

The study on recent advances in solar panel cleaning technology has revealed the following major researches. Natural removal of dust accumulated on solar panels [3,4] is accomplished in the presence of strong winds or 
heavy rains. However, they come with more disadvantages - the adverse effect of strong winds in dusty or desert regions will only lead to an increase in accumulated dust. Heavy rain will also not give uniform cleaning and can leave permanent scratches on the solar panel surface leading to decrease in solar panel output.

The second most common approach to cleaning of solar panel is by manual or mechanical removal by brushing or blowing. Brushing can also leave scratches on solar panel surface depending on quality of brush used and requires periodic maintenance especially in rainy weather conditions. Blowers have advantages in that solar panel surface remains unaffected, however, it alone does not sufficiently clean the surface especially when rain or humid conditions persist.

One of the most recent research is the application of self-cleaning nano films to the surface of solar panels. This film is made of $\mathrm{TiO} 2$, which has hydrophilicity and photocatalytic ability. However, this method is only efficient in all year round rainy weather conditions as it depends on dispersing the rain drops on the surface and using this dispersal property to carry the dust off the surface.

\section{Proposed Solar Panel Cleaning Method with Super Hydrophobic Coating}

The solar panel automatic cleaning method proposed here uses a 3 tier approach - Super-hydrophobic coating, sliding perforated blower and wiper arrangement.

This entire system is also designed to work on two strategies to ensure maximum solar panel efficiency -

1. Minimize the energy consumption for the auto cleaning arrangement, and

2. zero use of water.

Water is a scarce resource especially in the test region of the apparatus - Fujairah in the UAE. Fujairah is a typical desert region with clear skies for most of the year round and winter season spanning a few months when occasional rain is expected. The region is also known for its dusty sand storms, and high temperatures during summer.

The solar panel is coated with a super-hydrophobic nano ceramic coating which protects the solar panel surface from environmental factors and overheating. This coating is proven from experiments to facilitate easy dispersal of water and dust off the surface of the solar panel [5]. The super-hydrophobic coating over the solar panel acts similar to the natural super hydrophobic coating found over lotus leaves. This coating acts as natural dust and water repellent, keeping the surface of the solar panel predominantly clean and protecting it from heated up due to the high temperatures found in the region.

TABLE I: Efficiency Calculations

\begin{tabular}{lll}
\hline \hline $\begin{array}{l}\text { Solar Panel } \\
\begin{array}{l}\text { Operating Climatic } \\
\text { Condition }\end{array}\end{array}$ & $\begin{array}{l}\text { Efficiency Recorded } \\
\text { Before Cleaning } \\
\text { System Installation }\end{array}$ & $\begin{array}{l}\text { Efficiency Recorded } \\
\text { After Cleaning } \\
\text { System Installation }\end{array}$ \\
\hline Clear Sunny & $100 \%$ & $100 \%$ \\
Dust - Wind & $81.5 \%$ & $100 \%$ \\
Dust and Rain & $77 \%$ & $97.3 \%$ \\
\hline
\end{tabular}

The cleaning is further enhanced by an automatic HIL perforated sliding blower and wiper arrangement. The hardware parts are controlled by feedback control incorporated by Arduino (programmable micro controller kit) programming, timed triggers and sensor data.

The perforated clean energy based blower is set to operate on a timed basis triggered by the Arduino program. This step ensures the solar panel is cleaned off dust or sand which is more common in this region.

The wiper arrangement will be triggered only on positive feedback received from the rain drop sensor. This set up further ensures minimizing the energy consumption of the auto cleaning system. Exceptional efficiency is maintained by this cleaning system. 
The table 1 lists the efficiency noted from the experiment under different weather conditions, recorded before and after implementing the auto self-cleaning system.

\section{Conclusion}

This paper has presented an industrially manufacture-able viable design for efficient automatic cleaning of solar panels operating on clean energy without utilizing water. The super-hydrophobic coating along with the perforated blower and wiper arrangement is an innovative design capable of implementing on existing PV solar panels and new generation curved solar panels.

\section{References}

[1] Elminir H K, Ghitas A E, Hamid R H, et al. Effect of dust on the transparent cover of solar collectors. Energy Conversion Management, 2006; 47: 3192-3203.

https://doi.org/10.1016/j.enconman.2006.02.014

[2] Mazumdera M K, Sharmaa R, Birisa A S, et al. Self-cleaning transparent dust shields for protecting solar panels and other devices. Particulate Science and Technology, 2007; 25: 5-20.

https://doi.org/10.1080/02726350601146341

[3] Gaier J, Davis P, Marabito M. Aeolian removal of dust types from photovoltaic surfaces on Mars. 16th AIAA/NASA/ASTM/IES Space Simulation Conference. NM: Albuquerque, 1990.

[4] Gaier J, Davis P. Effect of particle size of Martian dust on the degradation of photovoltaic cell performance, NASA TM-105232, 1992

[5] Park Y B, Im H, Im M, et al. Self-cleaning effect of highly water-repellent microshell structures for solar cell applications. Journal of Materials Chemistry, 2011; 21:633-636.

https://doi.org/10.1039/C0JM02463E 